\title{
B-Myb switches from Cyclin/Cdk-dependent to Jnk- and p38 kinase-dependent phosphorylation and associates with SC35 bodies after UV stress
}

\author{
E Werwein $^{1,2}$, M Dzuganova $^{1}$, C Usadel ${ }^{1}$ and K-H Klempnauer ${ }^{*, 1}$
}

B-Myb is a highly conserved member of the Myb transcription factor family that has essential roles in cell-cycle progression. Recent work has suggested that B-Myb is also involved in the cellular DNA-damage response. Here, we have investigated the fate of B-Myb in UV-irradiated cells. UV stress leads to the appearance of phosphorylated B-Myb in nuclear SC35 speckles during transcriptional shutdown. Furthermore, we show that UV irradiation leads to a change of the phosphorylation pattern of B-Myb, which is caused by a switch from Cyclin/Cdk-dependent to Jnk and p38 kinase-dependent phosphorylation. Taken together, we have identified Jnk and p38 kinase as novel regulators of B-Myb and established the localization of phosphorylated B-Myb in SC35 speckles as a potential novel regulatory mechanism for B-Myb in UV irradiated cells.

Cell Death and Disease (2013) 4, e511; doi:10.1038/cddis.2013.36; published online 28 February 2013

Subject Category: Cancer

B-Myb (v-myb myeloblastosis viral oncogene homolog (avian)-like 2) is a highly conserved transcription factor of the Myb family that is ubiquitously expressed in proliferating cells and has important roles in cell-cycle progression., ${ }^{1,2}$ Expression and activity of B-Myb are regulated during the cell cycle by a variety of mechanisms acting on the transcriptional and post-transcriptional level. Notably, phosphorylation of B-Myb by Cyclin A/cyclin-dependent kinase 2 (Cdk2) at the onset of S-phase stimulates its transactivation potential by relieving repressive effects exerted by its C-terminal domain. $^{3-8}$ The activity of B-Myb is affected by several interacting proteins, including cyclin D1, ${ }^{9,10}$ poly-(ADP-ribose) polymerase (PARP), ${ }^{11}$ nucleolin, ${ }^{12}$ p300, ${ }^{10,13}$ TAFII250 ${ }^{14}$ and nuclear receptor corepressor/silencing mediator for retinoid and thyroid hormone receptors (N-CoR/SMRT). ${ }^{15}$ The impact of some of these proteins, such as PARP, ${ }^{16} \mathrm{~N}-\mathrm{CoR} / \mathrm{SMRT}^{15}$ and $\mathrm{p} 300,{ }^{10}$ is modulated by phosphorylation of B-Myb, suggesting that they are involved in the phosphorylationdependent control of B-Myb activity. Phosphorylation of B-Myb also triggers its degradation by the ubiquitindependent Cdc34-SCF ${ }^{\text {45Skp2 }}$ pathway. ${ }^{17}$ Although B-Myb levels are rather uniform in different cell types, embryonic stem cells express the protein at elevated levels, ${ }^{18,19}$ suggesting that B-Myb is particularly important during early embryogenesis. This is supported by the phenotype of B-myb knockout mice, which suffer early embryonic death due to proliferation defects of the cells of the inner cell mass. ${ }^{20}$
Recent work in Drosophila and in mammalian cells has demonstrated that B-Myb is part of a multiprotein complex that regulates genes at the $\mathrm{G} 2 / \mathrm{M}$ transition of the cell cycle. The Drosophila RBF, E2 promoter-binding factor (E2F) and Myb-interacting proteins (DREAM) complex ${ }^{21,22}$ consists of dmMyb and several other proteins, including the Drosophila homologs of E2F2 and retinoblastoma and the Myb-interacting proteins Mip40, Mip120 and Mip130, and has been implicated in the transcription of G2/M phase genes. ${ }^{23,24}$ In mammalian cells, a similar complex termed LINC (abnormal lineage complex), consisting of E2F4 and either p130 or p107 and Lin-9, Lin-37, Lin-54 and Lin-5, has been identified. ${ }^{25-27}$ In resting cells, LINC represses E2F target genes whereas in S-phase, LINC switches to B-Myb to activate genes required for the G2/M transition and mitosis. ${ }^{25,26,28,29}$ It was demonstrated that B-Myb targets LINC to the promoters of G2/M genes, thereby activating their transcription. ${ }^{27,28,30}$ Apart from its role as a transcription factor, B-Myb also performs non-transcriptional roles during mitosis. In the Myb-Clafi complex, B-Myb is required together with clathrin and filamin for mitotic spindle formation, ${ }^{31}$ emphasizing the role of B-Myb during mitosis. Recently, B-Myb was shown to stimulate G1/S transition independently of its sequence-specific DNA-binding activity and to affect the DNA-replication program, further highlighting the complex manner of cell-cycle regulation by B-Myb. 32,33

In addition to its cell-cycle function, several observations suggest a role of B-Myb in the DNA damage response. Using

\footnotetext{
${ }^{1}$ Institut für Biochemie, Wilhelm-Klemm-Straße 2, D-48149 Münster, Germany and ${ }^{2}$ Graduate School of Chemistry (GSC-MS), Westfälische-Wilhelms-Universität Münster, Wilhelm-Klemm-Straße 2, Münster D-48149, Germany

${ }^{*}$ Corresponding author: K-H Klempnauer, Institut für Biochemie, Westfälische-Wilhelms-Universität, Wilhelm-Klemm-Straße 2, Münster D-48149, Germany. Tel: + 49251 8333203; Fax: + 49251 8333206; E-mail: klempna@uni-muenster.de

Keywords: B-Myb; SC35; Jnk; p38; phosphorylation

Abbreviations: B-Myb, v-myb myeloblastosis viral oncogene homolog (avian)-like 2; Cdk, cyclin-dependent kinase; E2F, E2 promoter-binding factor; GFP, green fluorescent protein; GST, gluthatione S-transferase; HSP70, heat-shock protein $70 \mathrm{kDa}$; IP, immunoprecipitation; Jnk, c-Jun N-terminal kinase; LINC, abnormal lineage complex; Myb, myeloblastosis; N-CoR/SMRT, nuclear receptor corepressor/silencing mediator for retinoid and thyroid hormone receptors; SAF-B, scaffold attachment factor B; SC35, serine/arginine-rich splicing factor 2; UV, ultraviolet; YFP, yellow fluorescent protein

Received 29.10.12; revised 30.11.12; accepted 05.12.12; Edited by G Raschella'
} 
chicken DT40 cells as a model system, we have shown that $\mathrm{B}-\mathrm{Myb}$ is required for the survival of cells treated with agents that induce DNA damage. ${ }^{34}$ Recent work in mammalian cells has shown that the interaction of B-Myb with the LINC complex is disrupted after induction of DNA damage and, furthermore, that $B-M y b$ is required for the recovery from a DNA damage-induced cell-cycle arrest. $^{35}$ To better understand the role of $\mathrm{B}-\mathrm{Myb}$ in the DNA-damage response, we have investigated the fate of B-Myb in cells irradiated with ultraviolet (UV) light.

\section{Results}

UV irradiation affects the phosphorylation of B-Myb and leads to the appearance of phosphorylated B-Myb in nuclear serine/arginine-rich splicing factor 2 (SC35) speckles. In proliferating cells, B-Myb is phosphorylated by CyclinA/Cdk2 at multiple sites in the C-terminal half of the protein. ${ }^{3-8,36}$ We used commercially available phosphorylation-specific antibodies against two known CyclinA/Cdk2 phosphorylation sites of B-Myb, Thr-487 and Ser-577, to see if UV irradiation affects the phosphorylation of B-Myb. Figure $1 \mathrm{~A}$ shows that both sites were affected differently by UV: Thr-487 phosphorylation slightly increased, whereas Ser-577 phosphorylation decreased.

To obtain further insight into the effects of UV irradiation and to see whether B-Myb associates with sites of DNA damage, we analyzed irradiated and non-irradiated cells by immunofluorescence microscopy, using antibodies against total B-Myb and B-Myb phosphorylated at Thr-487. Figure 1B shows that staining with B-Myb-specific antibodies revealed no obvious change in response to UV irradiation, whereas phospho-B-Myb(Thr-487)-specific antibodies revealed a pronounced speckled pattern after UV irradiation. Staining for phosphorylated Ser-577 showed a diffuse nuclear pattern in unirradiated cells whose intensity decreased after UV irradiation. We performed knockdown experiments with two different B-Myb-specific siRNAs to confirm that the speckled pattern was due to B-Myb (Figure 1C). B-Myb knock down caused a significant decrease of the staining pattern with both siRNAs. The appearance of phosphorylated B-Myb in the nuclear speckles was also observed in other human cell lines, such as MCF7 or Hela cells (Supplementary Figure S1a). Interestingly, a similar speckled pattern also appeared after heat shock (Supplementary Figure S1b). Overall, these experiments showed that UV irradiation or heat shock causes the appearance of B-Myb phosphorylated at Thr-487 in nuclear speckles.

To identify these subnuclear structures, we performed co-localization experiments (Figure 1D). The speckles detected with phospho-B-Myb(Thr-487) antibodies were also stained with antiserum against splicing factor SC35. Staining with antisera against scaffold attachment factor B (SAF-B; a marker for nuclear stress bodies), promyelocytic leukemia protein (Pml) or sites of DNA damage (using antibodies against $\gamma$-H2AX (H2A histone family member $\mathrm{X}$, pSer139)) showed no co-localization. We therefore concluded that B-Myb phosphorylated at Thr-487 associates with SC35 bodies after UV irradiation or heat stress.
UV-induced association of phospho B-Myb(Thr-487) with SC35 bodies is transient and coincides with a temporary shutdown of RNA-polymerase II-dependent transcription. To further characterize the association of phosphorylated B-Myb with SC35 bodies, we investigated the time course of the appearance of the speckled staining pattern after UV irradiation. As illustrated in Figure 2a, after a non-lethal UV dose the speckled pattern appeared over a period of approximately $4 \mathrm{~h}$, remained until $8 \mathrm{~h}$ and declined thereafter. UV irradiation leads to a temporary shutdown of RNA-polymerase II-dependent transcription, which eventually resumes when the cells recover. ${ }^{37}$ To investigate whether the transient association of phosphorylated B-Myb with SC35 speckles coincides with the inhibition and subsequent resumption RNA-polymerase II-dependent transcription, we stained nascent RNA by growing the cells in the presence of the nucleoside 5-ethynyl-uridine and subsequent visualization of the RNA by copper-catalyzed click chemistry with an azide derivative of Alexa Fluor 594. Non-irradiated cells (upper part of Figure 2c) showed a diffuse nuclear and a weak cytoplasmic staining of newly synthesized RNA. Additionally, an intense staining was observed in the nucleoli, presumably representing nascent ribosomal RNA. In UV-irradiated cells, the appearance of the speckled staining pattern for phosphorylated B-Myb coincided with reduction of the diffuse nuclear RNA staining, indicative of a UVdependent shutdown of RNA-polymerase II-dependent transcription in the nucleoplasm (middle part of Figure 2c). In these cells, the nucleolar RNA-polymerase I-dependent transcription persists, which is consistent with the observation that RNA-polymerase $\mathrm{I}$ is much less affected by UV irradiation than RNA-polymerase II. ${ }^{38}$ Furthermore, the disappearance of the speckled staining pattern for phosphorylated B-Myb coincided with the reappearance of the diffuse nuclear RNA pattern. This is seen in the bottom part of Figure 2c, where two cells with the speckled B-Myb pattern show low nucleoplasmic transcription, whereas two cells that show no speckled pattern for B-Myb show nucleoplasmic transcription similar to that of non-irradiated cells. Thus, in cells that have recovered from a non-lethal UV dose the disappearance of the speckled staining pattern for phosphorylated B-Myb coincides with the resumption of RNA-polymerase II-dependent transcription. As shown in Figure $2 \mathrm{~b}$, a high UV dose resulted in a faster and more persistent association of phosphorylated B-Myb with SC35 bodies. After $12-24 \mathrm{~h}$, the speckled staining pattern disappeared; however, those cells that no longer showed this pattern had a rounded morphology and appeared to be apoptotic, based on condensed nuclei as revealed by staining with DAPI dye (data not shown).

\section{B-Myb switches from Cdk-dependent to stress-inducible protein kinase-dependent phosphorylation after UV irradiation. Next, we were interested to know which protein kinase phosphorylates B-Myb after UV irradiation. Figure 3a shows that the Cdk inhibitor roscovitine decreased Thr-487 and Ser-577 phosphorylation in non-irradiated cells, confirm- ing that these sites are phosphorylated by CyclinA/Cdk2 in proliferating cells. After UV irradiation, roscovitine had no effect on Thr-487 phosphorylation, indicating that a different}


A
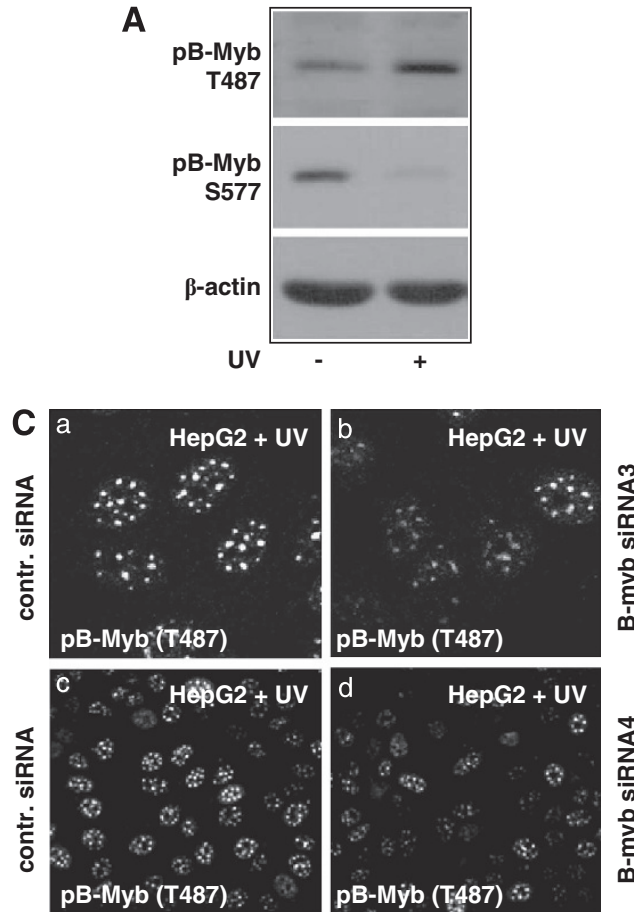

D
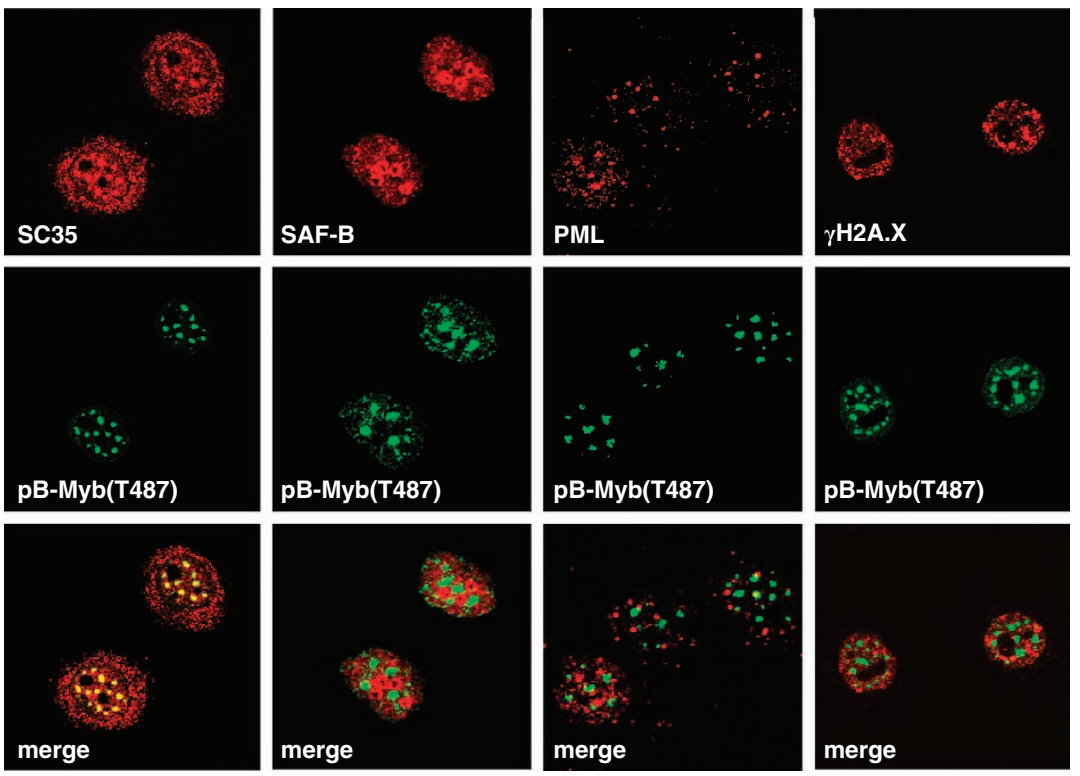

Figure 1 B-Myb phosphorylated at Thr-487 appears in nuclear SC35 speckles after UV irradiation of human cells. (A) Total cell extracts of untreated or UV-irradiated $\left(50 \mathrm{~J} / \mathrm{m}^{2}\right)$ HepG2 cells were analyzed by western blotting for the expression of B-Myb phosphorylated at Thr-487, Ser-577 and $\beta$-actin. (B) Untreated or UV-irradiated (50 J/m²) HepG2 cells were analyzed by immunofluorescence microscopy using antibodies against B-Myb, B-Myb phosphorylated at Thr-487 or B-Myb phosphorylated at Ser-577. Only the cell nuclei are visible. (C) HepG2 cells transfected with control siRNA or two different B-myb specific siRNAs were UV irradiated $\left(50 \mathrm{~J} / \mathrm{m}^{2}\right)$ and analyzed by immunofluorescence with antibodies specific for phosphorylated Thr-487. (D) HepG2 cells were UV irradiated and analyzed by immunofluorescence microscopy for co-localization of phospho-B-Myb(Thr-487) (green) with SC35, SAF-B, promyelocytic leukemia (PML) or $\gamma-\mathrm{H} 2 \mathrm{AX}$ (red). The bottom panel shows merged images with co-localization visible in yellow

kinase phosphorylates this site in UV-stressed cells. Because UV irradiation activates the c-Jun $\mathrm{N}$-terminal kinase (Jnk) and p38 kinase signaling pathways, we investigated whether these kinases were involved in the phosphorylation of B-Myb in UV-irradiated cells. Using the Jnk and p38 kinase inhibitors SP600125 and SB203580, we observed that both inhibitors partially inhibited the phosphorylation of Thr-487, whereas in combination they inhibited the phosphorylation completely (Figure 3a). This suggested that Jnk and p38 kinases act redundantly to phosphorylate B-Myb at Thr-487 after UV irradiation, as already shown for other proteins, such as Cdt1 or ATF-2. ${ }^{39,40}$ The observation that Ser-577 was not phosphorylated after UV irradiation indicated that these kinases act differentially on Thr-487 and Ser-577. 


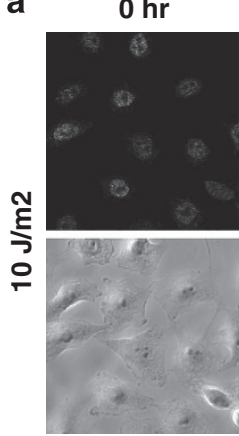

b
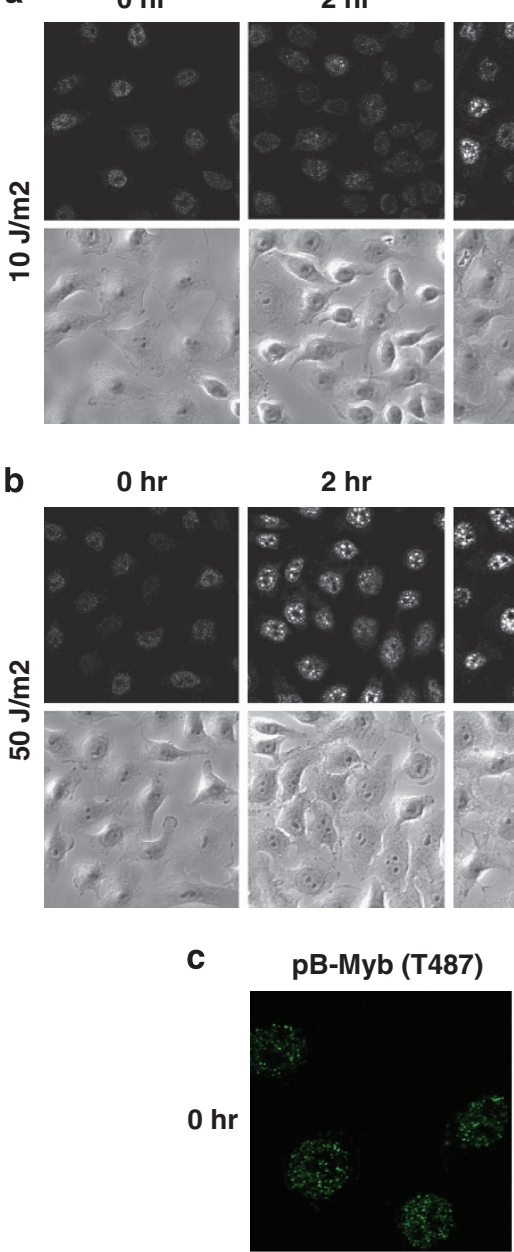

$2 \mathrm{hr}$
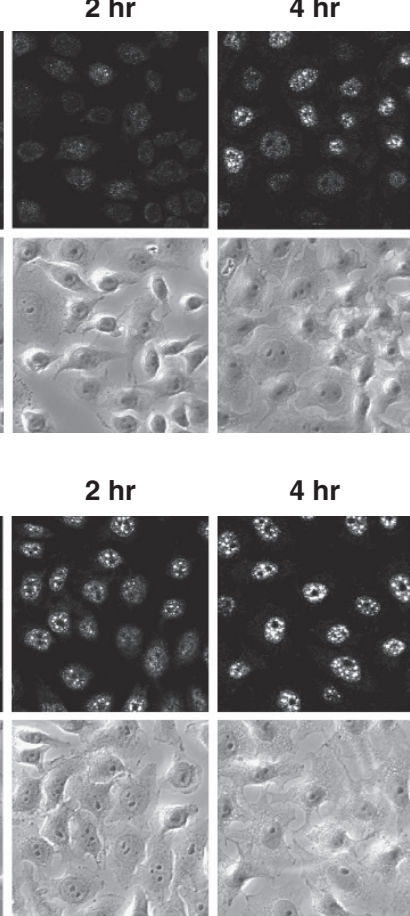

$4 \mathrm{hr}$
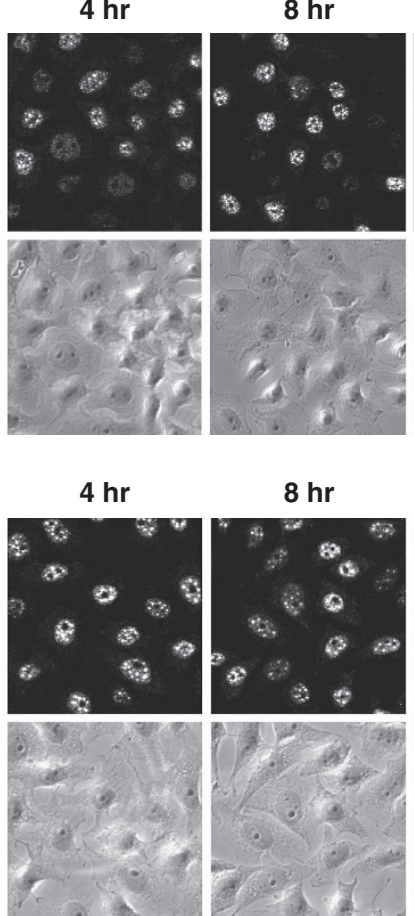

$8 \mathrm{hr}$
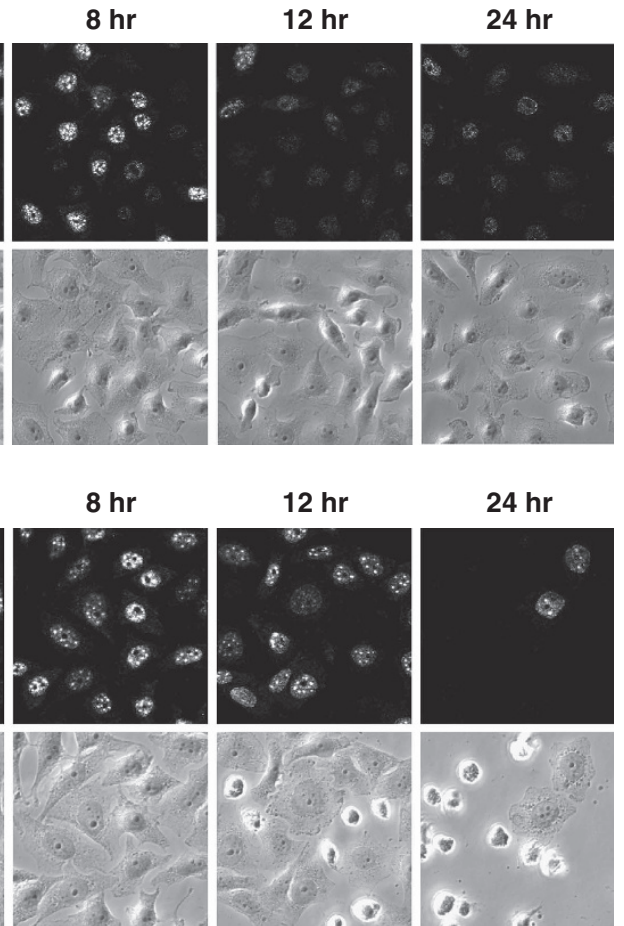

nascent RNA

\section{phase contrast}
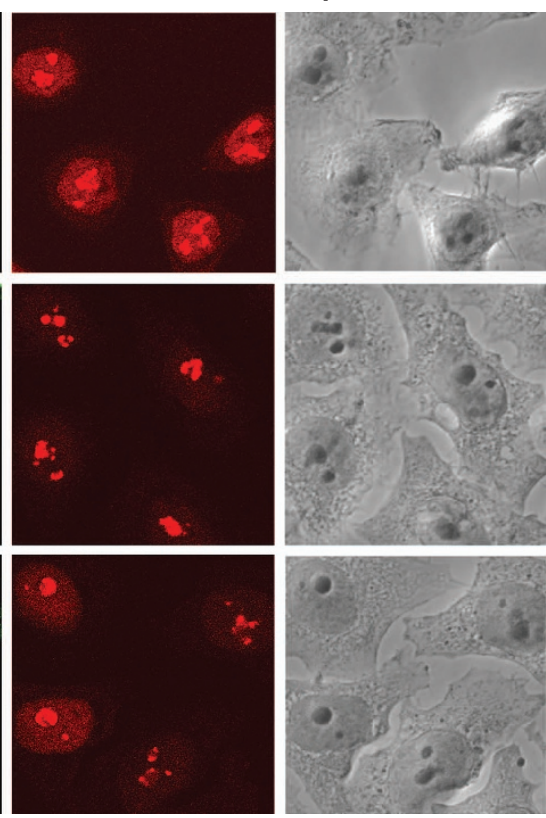

Figure 2 Speckle localization of phospho-B-Myb (Thr-487) after UV irradiation is transient and inversely correlated with transcription of nascent RNA. (a and b) HepG2 cells irradiated with the indicated doses of UV were analyzed at different times after irradiation by immunofluorescence microscopy using antibodies against phospho-BMyb(Thr-487). The bottom panels show the cells in phase contrast. (c) Non-irradiated or UV-irradiated $\left(10 \mathrm{~J} / \mathrm{m}^{2}\right)$ HepG2 cells were analyzed at different times after irradiation by immunofluorescence microscopy with antibodies against phospho-B-Myb(Thr-487) and staining of nascent RNA. Phase contrast pictures of the cells are shown on the right

The association of phospho-B-Myb(T487) with SC35 speckles was also inhibited by the combination of p38 and Jnk inhibitors but not by roscovitine (Figure 3b). Furthermore, treatment with anisomycin, an inducer of Jnk and p38 activity, led to the appearance of phospho-B-Myb(T487) in nuclear speckles. The effect of anisomycin could again be abolished by the Jnk and p38 inhibitors.
We used wild-type and Jnk1/Jnk2 double knockout mouse fibroblast lines ${ }^{41}$ to show that Jnk and p38 are involved in the phosphorylation of B-Myb in UV-stressed cells. Mouse B-Myb, in contrast to human B-Myb, showed a dose- and time-dependent electrophoretic mobility shift upon UV irradiation (Figure 4a). This shift was sensitive to phosphatase treatment (Figure $4 b$ ) and was suppressed by the combination 
a

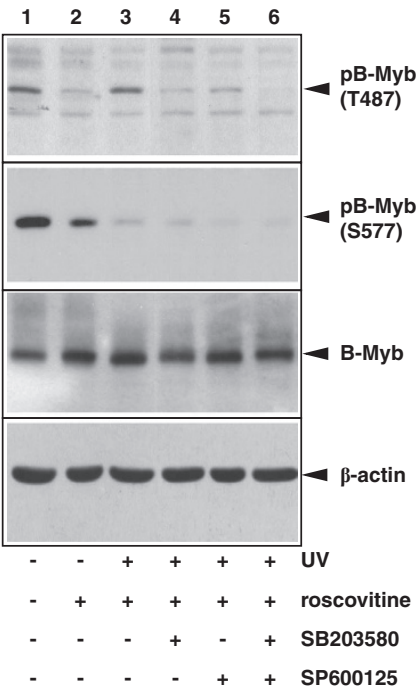

b

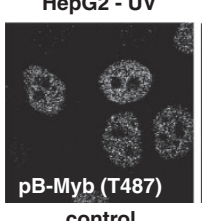

HepG2 - UV
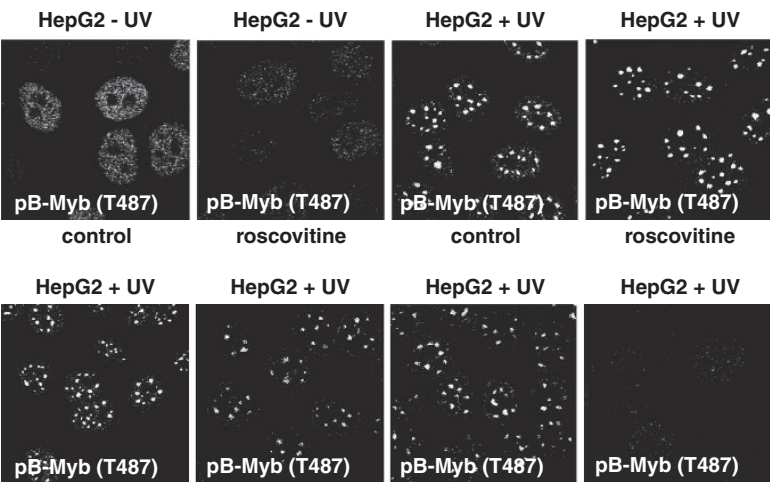

control
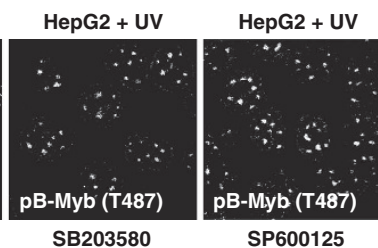

roscovitine

HepG2 + UV

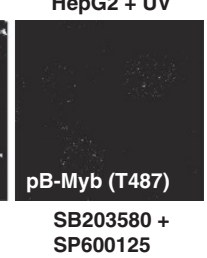

HepG2 - UV

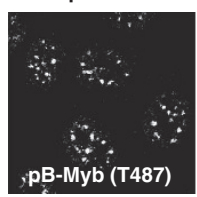

HepG2 - UV

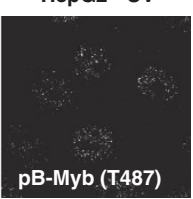

anisomycin +

SB203580 +

SP600125

Figure 3 UV-dependent phosphorylation and nuclear speckle localization of human B-Myb is abolished by Jnk and p38 kinase inhibitors. (a) HepG2 cells were UV irradiated in the presence or absence of roscovitine and the p38 and Jnk inhibitors SB203580 and SP600125. Total cell extracts were analyzed after $3 \mathrm{~h}$ with antibodies against B-Myb, phospho-B-Myb(Thr-487), phospho-B-Myb(Ser-577) and $\beta$-actin. (b) HepG2 cells treated as in panel (a) were analyzed by immunofluorescence microscopy with antibodies against phospho-B-Myb(Thr-487). In addition, non-irradiated cells were treated with anisomycin for $6 \mathrm{~h}$ in the absence or presence of SB203580 and SP600125 and analyzed as described above

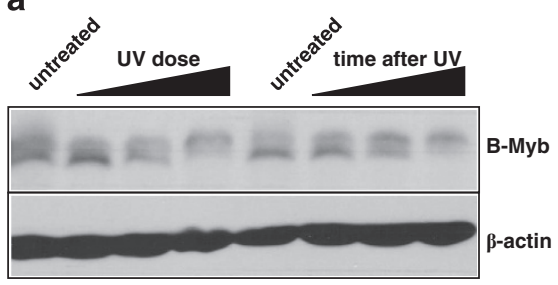

b

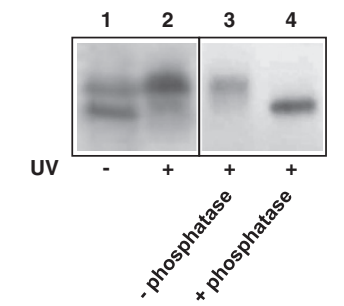

C

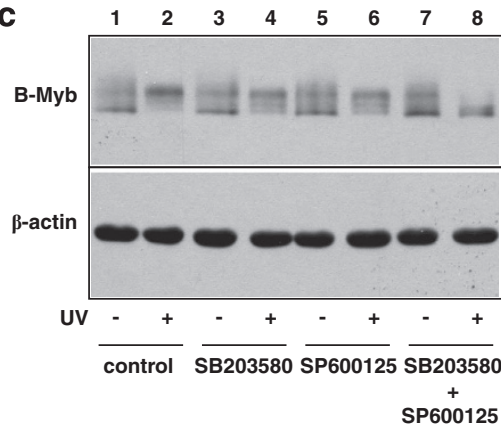

d

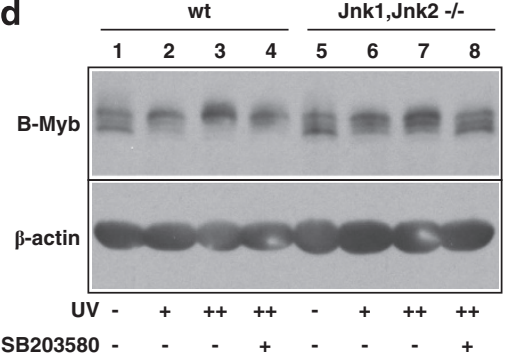

Figure 4 B-Myb is phosphorylated by P38 and Jnk kinases after UV irradiation. (a) 3T3-L1 mouse fibroblasts were UV irradiated with increasing doses or allowed to recover for different times after UV treatment. UV doses ranged from 10-50 J/m (3-h recovery) and recovery times were from 1 to $3 \mathrm{~h}$ (UV dose $\left.50 \mathrm{~J} / \mathrm{m}^{2}\right)$. (b) Untreated or UV-irradiated $\left(50 \mathrm{~J} / \mathrm{m}^{2}\right)$ 3T3-L1 mouse fibroblasts were analyzed $3 \mathrm{~h}$ after UV irradiation by western blotting with antiserum against B-Myb and $\beta$-actin (lanes 1 and 2). B-Myb immunoprecipitated from extracts of UV-irradiated 3T3-L1 cells was incubated with or without phosphatase before western blot analysis (lanes 3 and 4). (c) 3T3-L1 mouse fibroblasts were UV irradiated in the presence of the indicated kinase inhibitors. Control cells were treated in the same way except that they were not UV irradiated or supplied with dimethyl sulfoxide instead of the inhibitors. Cells were analyzed after $3 \mathrm{~h}$ by western blotting. (d) Wild-type or Jnk1/Jnk2 double knockout mouse fibroblasts were treated with increasing UV doses in the absence or presence of the p38 inhibitor SB203580 and analyzed as in panel (a)

of Jnk and p38 kinase inhibitors (Figure 4c). Furthermore, a similar shift was observed after heat shock or treatment with anisomycin (Supplementary Figure S2). Jnk1/Jnk2 double knockout fibroblasts also showed an UV-induced mobility shift of B-Myb; however, the shift appeared to be less prominent in the knockout than in the wild-type cells, especially at a higher 
a

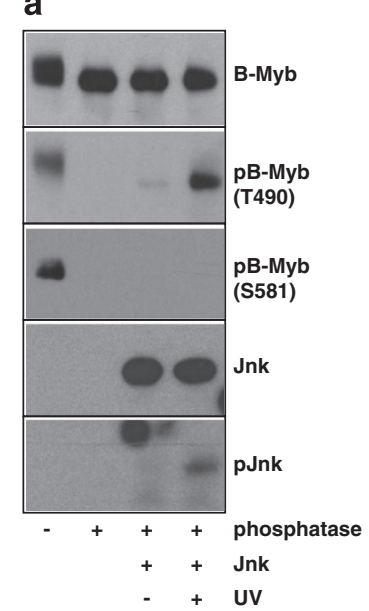

b

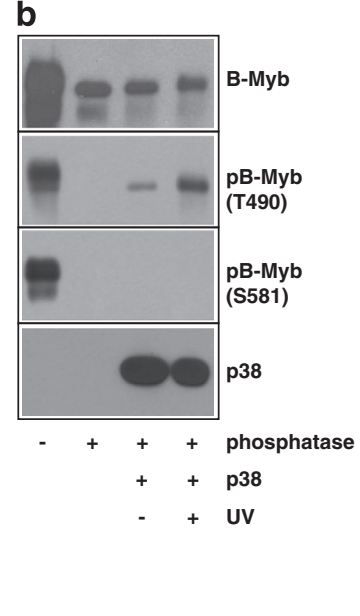

c

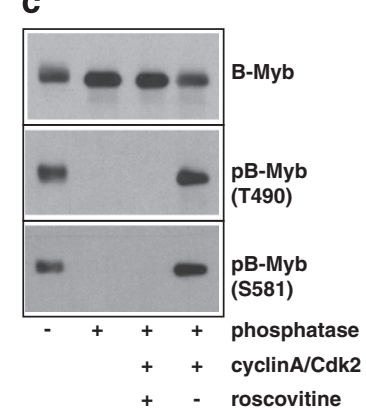

Figure 5 In vitro phosphorylation of B-Myb by Jnk1 and p38 $\alpha$. (a) A YFP-mouseB-Myb fusion protein purified from transfected cells using 'GFP-trap' beads was treated with phosphatase and then incubated with immunopurified Jnk1 isolated from UV-irradiated or unirradiated cells. YFP-B-Myb was then analyzed with antisera against phosphorylated Thr-490 or Ser-581. The presence and activation of Jnk1 in the in vitro kinase reactions was assessed with antibodies against Jnk1 and phosphorylated Jnk1. (b) YFP-B-Myb was phosphorylated by immunopurified p38 $\alpha$, as described in panel (a). (c) YFP-B-Myb was phosphorylated by immunopurified cyclin A/Cdk2 in the presence or absence of roscovitine

UV dose (compare lanes 3 and 7 of Figure 4d). Addition of the p38-inhibitor SB203580 alone was not sufficient to suppress the mobility shift in wild-type cells (Figure 4d, lane 4), whereas in Jnk1/Jnk2 knockout cells the UV-induced mobility shift was suppressed by SB203580 (Figure 4d, lane 8). This indicated that p38 kinase and Jnk1 or Jnk2 or both are able to induce the phosphorylation of B-Myb after UV irradiation. Further experiments showed that SB203580 was not able to suppress the mobility shift in Jnk1 and Jnk2 single knockout cells, indicating that both Jnk kinases act redundantly to phosphorylate B-Myb (Supplementary Figure S3). Overall, these experiments confirmed that Jnk1, Jnk2 and p38 kinase phosphorylate B-Myb in UV-stressed cells.

Phosphorylation of B-Myb by Jnk1 and p38 $\alpha$ in vitro. To demonstrate the UV-induced phosphorylation of B-Myb by Jnk and p38 more directly, we performed in vitro kinase assays using immunopurified kinases and a yellow fluorescent protein (YFP)-mouse-B-Myb fusion protein isolated from transfected cells by binding to green fluorescent protein '(GFP)-trap' beads. Subsequently, the beads with bound YFP-B-Myb were treated with phosphatase to erase phosphorylations that had occurred in the transfected cells. As shown in Figure 5a, Jnk1 isolated from non UV-irradiated cells phosphorylated Thr-490 (which corresponds to Thr-487 of human B-Myb) weakly, whereas activated Jnk1 from UV-irradiated cells induced a much stronger phosphorylation. Ser-581 of mouse B-Myb (which corresponds to Ser-577 of human B-Myb) was not phosphorylated by Jnk1, recapitulating the in vivo situation after UV stress and confirming the specificity of the in vitro assay. Western blotting with antibodies against Jnk1 showed that equal amounts of the kinase were present in both assays, and phospho-Jnk1specific antibodies confirmed the activation of the kinase after UV irradiation. A similar experiment with immunopurified $\mathrm{p} 38 \alpha$ showed that Thr-490 was phosphorylated in a UV-dependent manner, whereas Ser-581 was not phosphorylated (Figure 5b). Cyclin A/Cdk2 phosphorylated Thr-490 as well as Ser-581 (Figure 5c), demonstrating that the lack of phosphorylation of Ser-581 by Jnk1 and p38 $\alpha$ was not an inherent limitation of the assay but that it reflected the specificity of the kinases. Taken together, these experiments showed that UV-activated Jnk1 and p38 $\alpha$ are able to phosphorylate Thr-490 but not Ser-581 of mouse B-Myb.

Next, we performed gluthatione $S$-transferase (GST)pulldown assays using a panel of GST/B-Myb fusion proteins to see whether Jnk1 and p38 $\alpha$ are able to interact with B-Myb. Sepharose beads loaded with comparable amounts of different GST constructs were incubated with cell extracts containing Jnk1 or $\mathrm{p} 38 \alpha$ and bound proteins were subsequently detected by western blotting. Figures $6 a$ and b show that B-Myb was able to recruit both kinases; however, the binding regions for Jnk1 and $\mathrm{p} 38 \alpha$ were different. Jnk1 interacted strongly with a region in the center of B-Myb, harboring the transactivation domain of B-Myb (referred to as domain 2), and less strongly with the C-terminal domain of B-Myb. p38 $\alpha$ did not interact with the transactivation domain; however, strong interaction occurred to the part of B-Myb that lies C-terminally to the transactivation domain (referred to as D3) as well as to the C-terminal domain of B-Myb. Figure 6c shows a hypothetical model that is based on these results.

To finally address whether Jnk1 and $\mathrm{p} 38 \alpha$ are able to interact with B-Myb in vivo, we performed co-immunoprecipitation experiments using cells transfected with expression vectors for mouse B-Myb and Jnk1. We observed a transient interaction of B-Myb and Jnk1 after UV irradiation that reached its maximum 90 min after UV treatment (Figure 7a, left panels). The phosphorylation of B-Myb at Thr-490 was strongly increased and also showed a peak at the same timey whereas the phosphorylation at Ser-581 was decreased (bottom panels of the left part of Figure 7a). Interestingly, the UV-induced activation of the kinase, assayed with phospho-Jnk antibodies, occurred faster than the maximum of the binding of Jnk1 to B-Myb. This suggested that the 
a

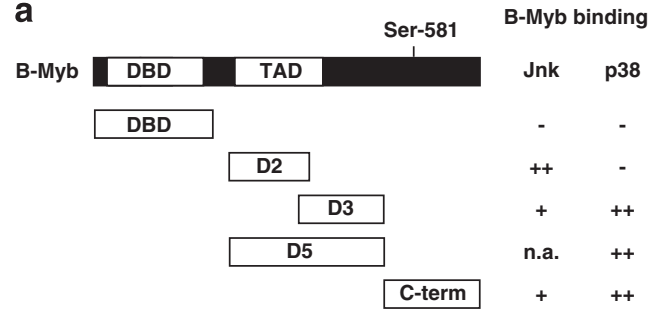

C

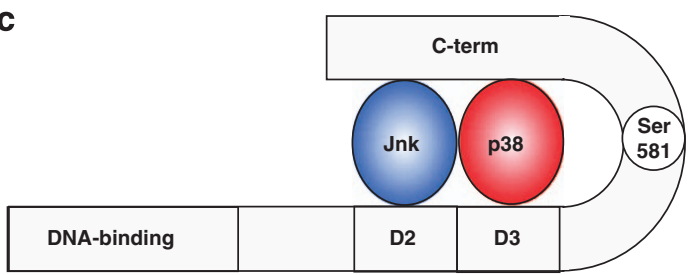

b
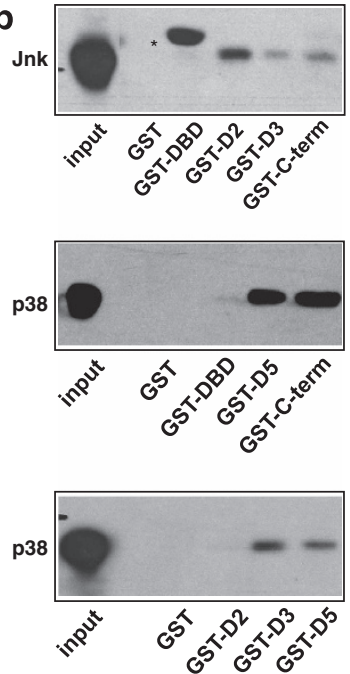

Figure 6 Interaction of B-Myb with Jnk1 and p38 $\alpha$ in vitro. (a) Schematic overview of GST-B-Myb constructs and summary of binding results for Jnk1 and p38 $\alpha$. (b) GSTpulldown was performed with extracts of cells transfected with expression vectors for Jnk1 (top panel) or p38 $\alpha$ (middle and bottom panels). Total cell extracts (input) and proteins bound to sepharose beads loaded with comparable amounts of the indicated GST-B-Myb proteins were analyzed by western blotting with antibodies against Jnk1 or p38 $\alpha$. Input represents $5-10 \%$ of cell lysates used for in vitro binding. The asterisk indicates a background band derived from the GST-DBD (GST-DNA-binding domain) protein. (c) Hypothetical model for interaction of B-Myb with Jnk1 and p38 $\alpha$. TAD, transactivation domain

a

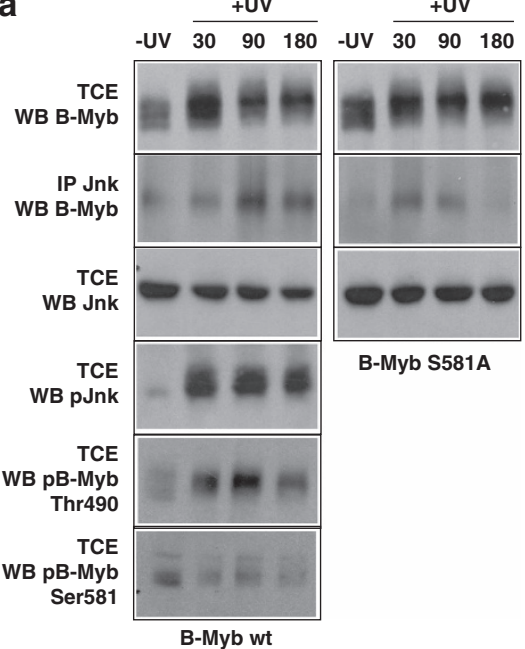

b

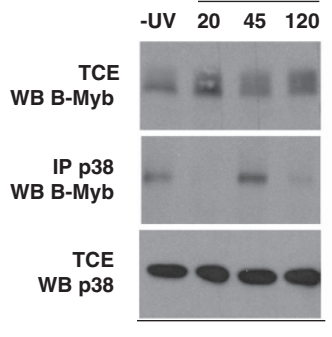

B-Myb wt

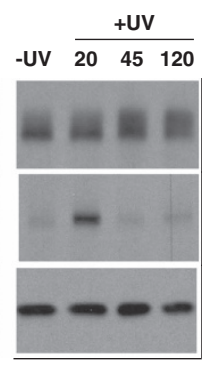

B-Myb S581A

Figure 7 Mutation of Ser-581 of mouse B-Myb promotes interaction with Jnk1 and p38 $\alpha$ after UV irradiation. QT6 cells were transfected with expression vectors for (a) wild-type mouse B-Myb or B-Myb(S581A) and Jnk1 and (b) wild-type B-Myb or B-Myb(S581A) and p38 $\alpha$. The cells were UV irradiated $\left(30 \mathrm{~J} / \mathrm{m}^{2}\right)$ and harvested after the indicated times. Aliquots of the total cell extracts (TCE) were then analyzed by western blotting (WB) with antibodies against B-Myb and Jnk or p38 kinase. Additionally, cell extracts were immunoprecipitated (IP) with antibodies against Jnk1 (a) or p38 $\alpha$ (b) and then analyzed by western blotting with antibodies against B-Myb and B-Myb phosphorylated at Thr-490 or Ser-581, as indicated. Input represents $5 \%$ of cell lysates used for immunoprecipitation

UV-induced binding to B-Myb was not simply due to the phosphorylation of the kinase. We considered the possibility that the phosphorylation state of Ser-581 might have a role in the interaction of Jnk1 and B-Myb. To address this possibility, we used a mouse B-Myb mutant in which serine 581 was replaced by alanine. As shown in the right panels of Figure 7a, the maximum of the interaction of the mutant B-Myb and Jnk1 already occurred $30 \mathrm{~min}$ after UV irradiation. This suggested that Ser-581 has a critical role in the interaction of B-Myb and Jnk and that the non-phosphorylated state of Ser-581 facilitates the binding of Jnk1. Analysis of the binding of p38 $\alpha$ to B-Myb showed p38 $\alpha$ also transiently interacts with B-Myb after UV irradiation and that interaction occurred faster when Ser-581 was replaced by alanine (Figure $7 \mathrm{~b}$ ). This suggests that the phosphorylation state of Ser-581 has a key role in the interaction and subsequent phosphorylation of B-Myb by Jnk1 and p38 $\alpha$ after UV stress.

\section{Discussion}

In contrast to its role during normal cell-cycle progression, much less is known about the function of B-Myb in cells 
challenged by DNA-damaging agents or other kinds of stress. Previous work has provided evidence for an anti-apoptotic role of B-Myb in cells that were UV irradiated or treated with a DNA alkylating agent. ${ }^{34}$ Mannefeld et $a{ }^{35}$ have shown that $\mathrm{B}-\mathrm{Myb}$ dissociates from the LINC complex upon induction of DNA damage by treatment with doxorubicin. Furthermore, they showed that B-Myb is required for re-entry into the cell cycle after recovery from the DNA damage-induced cell-cycle block. Apart from genotoxic stress, B-Myb also appears to have a role in heat-stressed cells: Santilli et al ${ }^{16}$ have demonstrated that B-Myb supports the survival of cells after thermal stress by activating the transcription of the ApoJ/ clusterin gene. Along similar lines, we have previously implicated B-Myb in the activation of the promoter of the heat-shock protein $70 \mathrm{kDa}$ (HSP70) gene via the so-called heat-shock element. ${ }^{42}$ In summary, these observations suggest that B-Myb has a critical role in response to genotoxic or other forms of stress. The work presented here confirms and extends this idea in several directions.

Our data show that UV stress affects B-Myb in at least two ways: first, it induces the transient appearance of a fraction of B-Myb phosphorylated at Thr-487 in SC35 speckles, also known as interchromatin granule clusters. SC35 domains are dynamic structures that are enriched in certain proteins, especially in various splicing factors (such as SC35) and contain little or no DNA. ${ }^{43}$ They are thought to be storage, assembly and modification compartments that serve to supply proteins to active transcription sites. ${ }^{44}$ This view is based on the observation that they contain proteins involved in transcription, such as RNA polymerase II subunits, the coactivator p300/CBP or the transcription elongation factor $\mathrm{P}-\mathrm{TEFb},{ }^{45,46}$ although transcription does not take place in the interchromatin granule clusters. The extent of co-localization of RNA polymerase II with interchromatin granule clusters is higher in cells inactivated for transcription by drugs or heat shock than in actively transcribing cells, ${ }^{47}$ also supporting the idea that they are storage places for factors not needed under these conditions. Following this notion, the speckle localization of B-Myb might serve to transiently store B-Myb until cell proliferation resumes. This is consistent with the transient nature of the speckled staining pattern for B-Myb and the observation that the resumption of RNA-polymerase II transcription coincides with the disappearance of phosphorylated B-Myb from the nuclear speckles (Figure 3c).

Another interesting aspect of SC35 speckles pointing to a slightly different direction is that they are located close to active transcription sites, which has led to the idea that they are functional centers that organize active genes on their periphery. ${ }^{48}$ The HSP70 gene is an example of a speckleassociated gene that associates in a promoter-dependent manner with the periphery of SC35 speckles after heat shock. ${ }^{49,50}$ As mentioned before, B-Myb is a strong activator of the HSP70 promoter, ${ }^{42}$ furthermore, we found that HSP70 expression is decreased after B-Myb knock down (unpublished data), indicating that the HSP70 gene is a bona fide B-Myb target gene. The speckle-localized B-Myb might therefore be involved in the transcription of certain genes, which are located close to the speckles. In this regard it is interesting to note that speckle-localized B-Myb was also observed in heat-shocked cells, that is, when the HSP70 gene is located in the vicinity of the speckles. ${ }^{50}$

The second effect of UV irradiation on B-Myb is a switch from Cyclin/Cdk-dependent to Jnk- and p38 kinase-dependent phosphorylation. This kinase switch is accompanied by an altered phosphorylation pattern of B-Myb at Thr-487 and Ser-577, which appears to be due to the inability of Jnk or p38 kinase to phosphorylate Ser-577 (or Ser-581 in the murine protein). Ser-577/581, in turn, seems to have a key role in the kinase switch as its de-phosphorylated state appears to stimulate binding of Jnk and p38 kinase to B-Myb. These findings are interesting because they implicate Jnk and p38 kinase as novel regulators of B-Myb under stress conditions. The observation that several stress-inducible kinases (Jnk1, Jnk2 and p38) target B-Myb indicates a high degree of redundancy and suggests an important role for the phosphorylation of B-Myb under stress conditions. Furthermore, our findings demonstrate for the first time that B-Myb is not simply regulated by global phosphorylation at many sites but that distinct phosphorylation patterns exist that might have specific functions. B-Myb has long been known to be phosphorylated by CyclinA/Cdk2 during normal cell-cycle progression at approximately 15 sites. $^{13,36}$ The impact of these phosphorylations on B-Myb function has only been studied globally so far: Cyclin/Cdk-dependent phosphorylation has been shown to increase the transactivation potential of B-Myb, to stimulate its acetylation by the co-activator p300 and to weaken the interaction of B-Myb with the co-repressor N-CoR/ SMRT. 5,6,10,13,15,36 Whether the phosphorylation of specific subsets of the phosphorylation sites, or even of individual sites, is responsible for these changes, is not clear so far. The observations that Ser-577/581 is phosphorylated differentially during normal cell-cycle progression and after UV stress and that its phosphorylation state apparently influences the binding of Jnk and p38 provides the first evidence for the idea that specific functional states of B-Myb are associated with specific phosphorylation patterns. The link between B-Myb and Jnk and p38 kinase is also interesting because several reports have revealed roles of JNK and p38 kinase during the unperturbed cell cycle, particularly in the G2-phase and the G2/M transition. ${ }^{39,51-54}$ This raises the intriguing possibility that B-Myb might also be regulated by these kinases under normal growth conditions.

We have not yet addressed the mechanism by which the phosphorylation state of Ser-577/581 affects the binding of Jnk and p38 kinase. In vitro binding data are consistent with the hypothetical model shown in Figure $6 c$ in which Jnk1 and p38 $\alpha$ interact with different regions (referred to as D2 and D3) in the central part as well as with the C-terminal part of B-Myb. At present, we do not know whether both kinases are able to bind simultaneously, whether they are direct physical interaction partners of B-Myb or whether other proteins mediate these interactions. Nevertheless, it is conceivable that the phosphorylation of Ser-577/581 disturbs these interactions, for example, by inducing a conformational change which diminishes the binding of the kinases to B-Myb. Such a model could explain why the UV-induced binding of the kinases to $B-M y b$ occurs faster in case of the S581A mutant than in case of wildtype B-Myb. In summary, we have identified Jnk and p38 kinase as novel regulators of B-Myb and established the 
localization of phosphorylated B-Myb in SC35 speckles as a potential novel regulatory mechanism for B-Myb in UV-irradiated cells.

\section{Materials and Methods}

Cells. Human HepG2, MCF7, Hela, HEK293, quail QT6 and mouse 3T3-L1 and knockout cells were grown in DMEM supplemented with $10 \%$ fetal calf serum. Mouse Jnk1 and Jnk2 single knockout, Jnk1/Jnk2 double knockout and wild-type fibroblasts were obtained from E Wagner. ${ }^{41}$ Cells were irradiated with UV-C in the presence of $5 \mathrm{ml}$ growth medium per $10 \mathrm{~cm}$ petri dish without the lid. After UV irradiation, the cells were allowed to recover for $3 \mathrm{~h}$, if not indicated otherwise Kinase inhibitors were added $3 \mathrm{~h}$ before UV treatment and used the following concentrations: roscovitine $(30 \mu \mathrm{M})$, SB203580 $(15 \mu \mathrm{M})$, and SP600125 $(40 \mu \mathrm{M})$. Anisomycin was used at $10 \mu \mathrm{g} / \mathrm{ml}$. Alternatively, cells were heat-shocked at $45^{\circ} \mathrm{C}$ for $30 \mathrm{~min}$ and allowed to recover for $1 \mathrm{~h}$ at $37^{\circ} \mathrm{C}$.

Immunofluorescence analysis and staining of nascent RNA. Cells were fixed with $2 \%$ paraformaldehyde in PBS for $10 \mathrm{~min}$, followed by incubation with $50 \mathrm{mM} \mathrm{NH}_{4} \mathrm{Cl}$ for $10 \mathrm{~min}$ at room temperature. The cells were then permeabilized with PBS containing $0.2 \%$ NP40 for $10 \mathrm{~min}$ at room temperature and immunostained with the desired primary antibodies. Anti-mouse immunoglobulins (A11030, Invitrogen, Darmstadt, Germany) or Alexa Fluor 488-coupled antirabbit (A11034, Invitrogen) immunoglobulins were used as secondary antibodies. Staining for B-Myb was performed with the B-Myb LX015.1 mouse monoclonal antibody, ${ }^{55}$ kindly provided by R. Watson. In addition, the following commercially available antibodies were used: rabbit anti phospho B-Myb Thr-487 (Abcam, Cambridge, UK, ab 76009), rabbit anti-phospho B-Myb Ser-577/581 (Abcam, ab 61000), mouse anti SC-35 (Millipore, Billirica, MA, USA, 04-1550), mouse anti SAF-B (Millipore, 05-588), rabbit anti Jnk (Santa Cruz, Santa Cruz, CA, USA, SC-571), mouse anti phospho-Jnk (Santa Cruz, SC-6254), mouse anti $\beta$-actin (Sigma-Aldrich, St. Louis, MO, USA, AC-15), mouse anti $\gamma$-H2AX (Abcam, ab 22551) and mouse anti promyelocytic leukemia (Santa Cruz, SC-966). For 5-ethynyl-uridine staining of nascent RNA, cells were pre-labeled with $1 \mathrm{mM}$ 5-ethynyl-uridine for $20 \mathrm{~min}$ before fixation. Copper-catalyzed click reactions were performed using click-iT EdU Alexa Fluor 594 Imaging kit (Invitrogen), following the protocol of the manufacturer. Images were acquired with Leica TCS SL confocal system using the Leica confocal software (Leica Microsystems, Wetzlar, Germany). For co-localization analysis, the images were acquired sequentially and merged electronically using Adobe Photoshop software (Adobe Systems incorporated, San Jose, CA, USA).

Expression vectors and transfections. Expression vectors for fulllength mouse B-Myb (pCDNA3-MuBMyb) has been described. ${ }^{42}$ pCDNA3MuBMyb(S581A) encodes mouse B-Myb with a single amino-acid substitution of serine 581 by alanine. The YFP-B-Myb expression vector was obtained by cloning the complete coding region for mouse B-Myb downstream of the coding region for the YFP in plasmid pYFP-C1. Prokaryotic expression vectors for GST-B-Myb fusion proteins contain full-length B-Myb (GST-B-Myb) or B-Myb amino acids 240-376 (GST-B-Myb D2), 349-536 (GST-B-Myb D3), 240-536 (GST-B-Myb D5), 534-704 (GST-B-Myb Cterm) and 1-190 (GST-B-Myb DNA-binding domain). Expression vectors for Flag-tagged Jnk1, Flag-tagged $\mathrm{p} 38 \alpha$, Cdk2 and GFP-tagged CyclinA1 were obtained from R.J. Davis, R. Weinberg and C. Müller-Tidow, respectively. Transient transfection of plasmid DNAs was performed by calcium phosphate co-precipitation, as described. ${ }^{18}$

RNA interference. B-Myb expression was silenced with siRNA duplexes targeting the sequences $5^{\prime}$-CUGGAACUCUACCAUCAAA-3' (B-myb siRNA_3), $5^{\prime}$-GAAACAUGCUGCGUUUGUA-3' (B-myb siRNA_4). siRNA targeting Renilla luciferase (5'-AAACAUGCAGAAAAUGCUG-3') was used as negative control. Cells were grown in six-well plates to approximately $50-80 \%$ confluence and received $1.5 \mathrm{ml}$ fresh growth medium before transfection. Then $100 \mathrm{nM}$ siRNA was transfected using Metafectene Pro (Biontex, San Diego, CA, USA), according to manufacturers' protocols. Cells were harvested $48 \mathrm{~h}$ later, and the level of knockdown was evaluated by western blotting or immunostaining, as appropriate.

Co-immunoprecipitation. Cells transfected with the desired expression vectors were lysed in ELB buffer $(50 \mathrm{mM}$ Tris/ $/ \mathrm{HCl} \mathrm{pH} 7,5 ; 120 \mathrm{mM} \mathrm{NaCl} ; 20 \mathrm{mM}$ $\mathrm{NaF} ; 1 \mathrm{mM}$ EDTA; $6 \mathrm{mM}$ EGTA; $15 \mathrm{mM}$ sodium pyrophosphate; $1 \mathrm{mM}$ phenylmethylsulfonyl fluoride; $0,2 \% \mathrm{NP}-40 ; 10 \%$ glycerol and a protease inhibitor mix containing Aprotinin, Leupeptin and Pepstatin). After incubation on ice for $30 \mathrm{~min}$, lysates were centrifuged at $14000 \times g$ for $30 \mathrm{~min}$, and the supernatant was used as total protein extract. Aliquots of the total protein extract were immunoprecipitated with the appropriate antibodies for 1 and up to $12 \mathrm{~h}$ at $4{ }^{\circ} \mathrm{C}$. Protein-G Sepharose beads were then added and incubated further for $3 \mathrm{~h}$ at $4{ }^{\circ} \mathrm{C}$ under constant agitation. Immune complexes bound to the beads were collected by centrifugation, washed five times with lysis buffer and finally subjected to SDS-PAGE. Proteins were transferred to nitrocellulose membranes and stained with the appropriate antibodies.

In vitro kinase assay. YFP-B-Myb was precipitated from extracts of transfected cells by incubation with 'GFP-trap' beads (Chromotec, München, Germany) and washing twice with ELB buffer and three times with phosphatase buffer $(50 \mathrm{mM}$ Tris/ $\mathrm{HCl}, \mathrm{pH} 8,5,5 \mathrm{mM} \mathrm{MgCl}$ ). The beads were then treated with five units FastAP phosphatase (Fermentas, Thermo Fisher Scientific, Inc, Waltham, MA, USA) for $1 \mathrm{~h}$ at $37^{\circ} \mathrm{C}$. The beads were then washed again twice with ELB buffer and three times with kinase buffer $(25 \mathrm{mM}$ Tris/ $/ \mathrm{HCl}, \mathrm{pH} 7,5,10 \mathrm{mM}$ $\mathrm{MgCl}_{2}, 5 \mathrm{mM} \beta$-glycerophosphate, $\left.2 \mathrm{mM} \mathrm{DTT}, 100 \mu \mathrm{M} \mathrm{Na}_{3} \mathrm{VO}_{4}\right)$. Jnk1, p38 $\alpha$ and Cdk2 kinases were immunoprecipitated from extracts of cells transfected with the corresponding expression vectors, using the appropriate tag-antibodies coupled to protein-G sepharose beads. The beads were also washed two times with ELBand three times with kinase buffer. Kinase reactions were performed by combining beads containing YFP-B-Myb and the desired kinase, adding $50 \mu \mathrm{M}$ ATP (final concentration) and incubating for $1 \mathrm{hr}$ at $37^{\circ} \mathrm{C}$. Reactions were stopped by adding SDS-sample buffer.

\section{Conflict of Interest}

The authors declare no conflict of interest.

Acknowledgements. We thank R. Watson for the monoclonal anti B-Myb antibody, E. Wagner and P. Angel for providing the mouse Jnk knockout cell lines and R.J. Davis, R. Weinberg and C. Müller-Tidow for plasmids. This work was supported by the DFG (KL461/14-1) and the Graduate School of Chemistry (GSC-MS) at the University of Muenster, Germany.

1. Joaquin M, Watson RJ. Cell cycle regulation by the B-Myb transcription factor. Cell Mol Life Sci 2003; 60: 2389-2401.

2. Sala A. B-Myb, a transcription factor implicated in regulating cell cycle, apoptosis and cancer. Eur J Cancer 2005; 41: 2479-2484.

3. Robinson C, Light Y, Groves R, Mann D, Marais R, Watson R. Cell-cycle regulation of B-Myb protein expression: specific phosphorylation during the $S$ phase of the cell cycle. Oncogene 1996; 12: 1855-1864.

4. Lane S, Farlie P, Watson R. B-Myb function can be markedly enhanced by cyclin A-dependent kinase and protein truncation. Oncogene 1997; 14: 2445-2453.

5. Sala A, Kundu M, Casella I, Engelhard A, Calabretta B, Grasso L et al. Activation of human B-MYB by cyclins. Proc Natl Acad Sci USA 1997; 94: 532-536.

6. Ziebold U, Bartsch O, Marais R, Ferrari S, Klempnauer K-H. Phosphorylation and activation of B-Myb by cyclin A-Cdk2. Curr Biol 1997; 7: 253-260.

7. Saville MK, Watson RJ. The cell-cycle regulated transcription factor B-Myb is phosphorylated by cyclin $\mathrm{A} / \mathrm{Cdk} 2$ at sites that enhance its transactivation properties. Oncogene 1998; 17: 2679-2689.

8. Bartsch O, Horstmann S, Toprak K, Klempnauer K-H, Ferrari S. Identification of cyclin A/Cdk2 phosphorylation sites in B-Myb. Eur J Biochem 1999; 260: 384-391.

9. Horstmann S, Ferrari S, Klempnauer K-H. Regulation of B-Myb activity by cyclin D1. Oncogene 2000; 19: 298-306.

10. Schubert S, Horstmann S, Bartusel T, Klempnauer K-H. The co-operation of B-Myb with the coactivator $p 300$ is orchestrated by cyclins A and D1. Oncogene 2004; 23: 1392-1404.

11. Cervellera MN, Sala A. Poly(ADP-ribose) polymerase is a B-MYB coactivator. J Biol Chem 2000; 275: 10692-10696.

12. Ying GG, Proost $P$, van Damme J, Bruschi $M$, Introna $M$, Golay J. Nucleolin, a novel partner for the Myb transcription factor family that regulates their activity. J Biol Chem 2000; 275 : 4152-4158.

13. Johnson LR, Johnson TK, Desler M, Luster TA, Nowling T, Lewis RE et al. Effects of B-Myb on gene transcription: phosphorylation-dependent activity and acetylation by $\mathrm{p} 300$. J Biol Chem 2002; 277: 4088-4097.

14. Bartusel T, Klempnauer K-H. Transactivation mediated by B-Myb is dependent on TAF(II)250. Oncogene 2003; 22: 2932-2941. 
15. Li X, McDonnell DP. The transcription factor B-Myb is maintained in an inhibited state in target cells through its interaction with the nuclear corepressors N-CoR and SMRT. Mol Cell Biol 2002; 11: 3663-3673.

16. Santilli G, Cervellera MN, Johnson TK, Lewis RE, lacobelli S, Sala A. PARP co-activates B-MYB through enhanced phosphorylation at cyclin/cdk2 sites. Oncogene 2001; 20: 8167-8174.

17. Charrasse S, Carena I, Brondani V, Klempnauer K-H, Ferrari S. Degradation of B-Myb by ubiquitin-mediated proteolysis: involvement of the Cdc34-SCF(p45Skp2) pathway. Oncogene 2000; 19: 2986-2995.

18. Kamano H, Burk B, Noben-Trauth K, Klempnauer K-H. Differential splicing of the mouse B-myb gene. Oncogene 1995; 11: 2575-2582.

19. Tarasov KV, Tarasova YS, Tam WL, Riordon DR, Elliott ST, Kania G et al. B-MYB is essential for normal cell cycle progression and chromosomal stability of embryonic stem cells. PLoS One 2008; 3: e2478.

20. Tanaka Y, Patestos NP, Maekawa T, Ishii S. B-myb is required for inner cell mass formation at an early stage of development. J Biol Chem 1999; 274: 28067-29070.

21. Korenjak M, Taylor-Harding B, Binné UK, Satterlee JS, Stevaux O, Aasland R et al. Native E2F/RBF complexes contain Myb-interacting proteins and repress transcription of developmentally controlled E2F target genes. Cell 2004; 119: 181-193.

22. Lewis PW, Beall EL, Fleischer TC, Georlette D, Link AJ, Botchan MR. Identification of a Drosophila Myb-E2F2/RBF transcriptional repressor complex. Genes Dev 2004; 23 : 2929-2940.

23. Georlette D, Ahn S, MacAlpine DM, Cheung E, Lewis PW, Beall EL et al. Genomic profiling and expression studies reveal both positive and negative activities for the Drosophila Myb MuvB/dREAM complex in proliferating cells. Genes Dev 2007; 21: 2880-2896.

24. Wen H, Andrejka L, Ashton J, Karess R, Lipsick JS. Epigenetic regulation of gene expression by Drosophila Myb and E2F2-RBF via the Myb-MuvB/dREAM complex. Genes Dev 2008; 22: 601-614

25. Schmit F, Korenjak M, Mannefeld M, Schmitt K, Franke C, von Eyss B et al. LINC, a human complex that is related to pRB-containing complexes in invertebrates regulates the expression of G2/M genes. Cell Cycle 2007; 6: 1903-1913.

26. Pilkinton M, Sandoval R, Colamonici OR. Mammalian Mip/LIN-9 interacts with either the p107, p130/E2F4 repressor complex or B-Myb in a cell cycle-phase-dependent context distinct from the Drosophila dREAM complex. Oncogene 2007; 26: 7535-7543.

27. Knight AS, Notaridou M, Watson RJ. A Lin-9 complex is recruited by B-Myb to activate transcription of G2/M genes in undifferentiated embryonal carcinoma cells. Oncogene 2009; 28: 1737-1747.

28. Sadasivam S, Duan S, DeCaprio JA. The MuvB complex sequentially recruits B-Myb and FoxM1 to promote mitotic gene expression. Genes Dev 2012; 26: 474-489.

29. Down CF, Millour J, Lam EW-F, Watson RJ. Binding of FoxM1 to G2/M gene promoters is dependent upon B-Myb. Biochim Biophys Acta 2012; 1819: 855-862.

30. Osterloh L, von Eyss B, Schmit F, Rein L, Hübner D, Samans B et al. The human synMuvlike protein LIN-9 is required for transcription of G2/M genes and for entry into mitosis. EMBO J 2007; 26: 144-157.

31. Yamauchi T, Ishidao T, Nomura T, Shinagawa T, Tanaka Y, Yonemura S et al. A B-Myb complex containing clathrin and filamin is required for mitotic spindle function. EMBO J 2008; 27: 1852-1862.

32. Lorvellec M, Dumon S, Maya-Mendoza A, Jackson D, Frampton J, García P. B-Myb is critical for proper DNA duplication during an unperturbed $S$ phase in mouse embryonic stem cells. Stem Cells 2010; 28: 1751-1759.

33. Werwein E, Schmedt T, Hoffmann H, Usadel C, Obermann N, Singer JD et al. B-Myb promotes S-phase independently of its sequence-specific DNA binding activity and interacts with polymerase delta-interacting protein 1 (Pdip1). Cell Cycle 2012; 11: 4047-4058.

34. Ahlbory D, Appl H, Lang D, Klempnauer K-H. Disruption of B-myb in DT40 cells reveals novel function for B-Myb in the response to DNA-damage. Oncogene 2005; 24: 7127-7134.

35. Mannefeld M, Klassen E, Gaubatz S. B-MYB is required for recovery from the DNA damage-induced G2 checkpoint in p53 mutant cells. Cancer Res 2009; 69: 4073-4080.

36. Johnson TK, Schweppe RE, Septer J, Lewis RE. Phosphorylation of B-Myb regulates its transactivation potential and DNA binding. J Biol Chem 1999; 274: 36741-36749.

37. Heine GF, Horwitz AA, Parvin JD. Multiple mechanisms contribute to inhibit transcription in response to DNA damage. J Biol Chem 2008; 283: 9555-9561.

38. Balajee AS, May A, Bohr VA. DNA repair of pyrimidine dimers and 6-4 photoproducts in the ribosomal DNA. Nucleic Acids Res 1999; 27: 2511-2520.

39. Chandrasekaran S, Tan TX, Hall JR, Cook JG. Stress-stimulated mitogen-activated protein kinases control the stability and activity of the Cdt1 DNA replication licensing factor. $\mathrm{Mol}$ Cell Biol 2011; 31: 4405-44016.

40. Mortona S, Davis RJ, Cohen P. Signalling pathways involved in multisite phosphorylation of the transcription factor ATF-2. FEBS Lett 2004; 572: 177-183.

41. Sabapathy K, Hochedlinger K, Nam SY, Bauer A, Karin M, Wagner EF. Distinct roles for JNK1 and JNK2 in regulating JNK activity and c-Jun-dependent cell proliferation. Mol Cell 2004; 15: 713-725.

42. Kamano H, Klempnauer K-H. B-Myb and cyclin D1 mediate heat shock element dependent activation of the human HSP70 promoter. Oncogene 1997; 14: 1223-1229.

43. Thiry M. The interchromatin granules. Histol Histopathol 1995; 10: 1035-1045.

44. Lamond Al, Spector DL. Nuclear speckles: a model for nuclear organelles. Nat Rev Mol Cell Biol 2003; 4: 605-612.

45. von Mikecz A, Zhang S, Montminy M, Tan EM, Hemmerich P. CREB-binding protein (CBP)/p300 and RNA polymerase II colocalize in transcriptionally active domains in the nucleus. J Cell Biol 2000; 150: 265-273.

46. Herrmann $\mathrm{CH}$, Mancini MA. The Cdk9 and cyclin T subunits of TAK/P-TEFb localize to splicing factor-rich nuclear speckle regions. J Cell Sci 2001; 114: 1491-1503.

47. Bregman DB, Du L, van der Zee S, Warren SL. Transcription-dependent redistribution of the large subunit of RNA polymerase II to discrete nuclear domains. J Cell Biol 1995; 129: 287-298.

48. Shopland LS, Johnson CV, Byron M, McNeil J, Lawrence JB. Clustering of multiple specific genes and gene-rich R-bands around SC-35 domains: evidence for local euchromatic neighborhoods. J Cell Biol 2003; 162: 981-990.

49. Jolly C, Vourch C, Robert-Nicoud M, Morimoto RI. Intron-independent association of splicing factors with active genes. J Cell Biol 1999; 145: 1133-1143.

50. Hu Y, Plutz M, Belmont AS. Hsp70 gene association with nuclear speckles is Hsp70 promoter specific. J Cell Biol 2010; 191: 711-719.

51. Cha $\mathrm{H}$, Wang $\mathrm{X}$, Fornace $\mathrm{LiH}, \mathrm{AJ} J \mathrm{~J}$. A functional role for $\mathrm{p} 38$ MAPK in modulating mitotic transit in the absence of stress. J Biol Chem 2007; 282: 22984-22992.

52. Tang J, Yang X, Liu X. Phoshorylation of Plk1 at Ser326 regulates its functions during mitotic progression. Oncogene 2008; 27: 6635-6645.

53. Gutierrez GJ, Tsuji T, Chen M, Jiang W, Ronai ZA. Interplay between Cdh1 andJNK activity during the cell cycle. Nat Cell Biol 2010; 12: 686-695.

54. Bogoyevitch MA, Yeap YYC, Qu Z, Ngoei KR, Yip YY, Zhao TT et al. WD40-repeat protein 62 is a JNK-phosphorylated spindle pole protein required for spindle maintenance and timely mitotic progression. J Cell Sci 2012; 125: 5096-5109.

55. Tavner F, Frampton J, Watson RJ. Targeting an E2F site in the mouse genome prevents promoter silencing in quiescent and post-mitotic cells. Oncogene 2007; 26: 2727-2735.

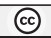

SOMERIEHISRESERV

published by Nature Publishing Group. This work is licensed under the Creative Commons Attribution-NonCommercialShare Alike 3.0 Unported License. To view a copy of this license, visit http://creativecommons.org/licenses/by-nc-sa/3.0/

\section{Supplementary Information accompanies this paper on Cell Death and Disease website (http://www.nature.com/cddis)}

